\title{
Ultrasound Therapy in the Treatment of Plantar Wart: A Case Study
}

\section{Poonam Dhankher ${ }^{1 *}$, Sakshi ${ }^{2}$ and Dimple Choudhry ${ }^{3}$}

\author{
${ }^{1}$ Assistant Professor, College of Physiotherapy, Pt.B.D.S, \\ University of Health Sciences, Rohtak, Haryana 124001 (INDIA). \\ 2 BPT Intern, College of Physiotherapy, Pt.B.D.S, \\ University of Health Sciences, Rohtak, Haryana 124001 (INDIA). \\ ${ }^{3}$ Assistant Professor, College of Physiotherapy, Pt.B.D.S, \\ University of Health Sciences, Rohtak, Haryana 124001 (INDIA). \\ E- mail: poonam.dhankher.jhajhria@gmail.com; Sakshijangra555@gmail.com \\ ; dimplephysio80@gmail.com
}

*Corresponding author: Poonam Dhankher; poonam.dhankher.jhajhria@gmail.com

\begin{abstract}
Verucae or plantar warts is a painful skin condition that demonstrates a high resistance to various treatments. They can be caused by trauma or human papilloma virus. The infection is mostly caused by a breach in the skin. The virus is usually contacted by walking barefoot in community swimming pool areas. The condition is common in sports persons. Our research focused on warts that occur on plantar surface of foot also known as plantar warts. They result in pain with pressure on weight bearing surfaces so walking is difficult and painful. Risk factors include using community showers barefoot, previous history of warts and decreased immune function.

Case Report: - We present a case report of a female aged 24 years who was clinically diagnosed with plantar wart. She developed recurrent plantar warts. For a year she was treated with pairing and punch excision with no success. Then ultrasound program was initiated with dosage of $0.6 \mathrm{watt} / \mathrm{cm}^{2}$ and increased up to $1 \mathrm{watt} / \mathrm{cm}^{2}$ for $15 \mathrm{~min}$ given at 1 -week interval for 15 weeks. At the end of $15^{\text {th }}$ week, the plantar wart had completely disappeared.
\end{abstract}

Keywords: plantar wart; ultrasonic therapy; punch excision

\section{INTRODUCTION}

Verruca Plantaris or plantar wart are dermatological lesions on the plantar aspect of foot caused by Human Papilloma Virus [1]. These are benign non-cancerous growths on the heel or balls of foot. They are a painful skin condition which upon weight bearing, makes walking difficult. A breach in the skin is required for the infection to occur. Plantar warts show an annual incidence of up to 14\% [2]. Warts constitute one of the most common virus infections of the skin, in particular of the hands and feet [3]. A plantar wart once it occurs on an individual, yields HPV through epithelial cells that desquamate from the area. The viral particles thus shed can infect other sites on the same individual and other individuals [4]. Risk factors for plantar warts involve having pre-existing plantar warts or having intimate contact with an individual having them [5,6]. Infection can occur via direct contact with a wart or fomites like socks, shoes etc can cause indirect contact [7]. Preexisting breach in the skin epidermis facilitates this and allows the entry of virus [8-10]. Warts tend to develop at areas of increased pressure on the plantar aspect of foot. Pressure points often have increased susceptibility to microtrauma which provides favourable ground for formation of warts.

Histologically, it is characterized by hyperkeratosis and may present as a hyperkeratotic papule [11]. Due to its location on the sole of foot, body weight creates pressure on it as a result the wart grows into the dermis and small part of it protrudes over skin surface.

The symptoms upon presentation includes visible hard corn present in the lateral aspect of sole of midfoot, pain while weight bearing and walking on barefoot i.e. any activity that increases the pressure on the plantar wart. When palpated warts often are tender and rough when compressed along the sides. [9] In this case plantar wart was most probably the result of wrong pattern of weight bearing and stresses imposed on foot due to over pronation of the foot.

The diagnosis is made clinically by dermatologist [12]. Biopsy can be done in case of diagnostic uncertainty or in cases of treatment refraction [13]. management of plantar warts produces a challenge because of a variability of treatment methods and each having variable response rates and possible adverse effects. [7] the most common treatment options for plantar warts are topical application of salicylic acid with pairing of the hyperkeratotic wart and cryotherapy with liquid nitrogen. 
$[14,15]$ The use of ultrasound therapy in the treatment of plantar warts has been proposed and the effectiveness has been proven in various studies [16-23].

Our study is an effort to study the effectiveness of ultrasonic therapy on the plantar wart for both pain reduction and for the healing of overlying skin.

\section{PATIENT INFORMATION AND CLINICAL FINDINGS}

The patient was a female aged 24 years; she was clinically diagnosed with plantar wart by a qualified dermatologist. Detailed history and physical examination, including the onset and nature of symptoms were recorded for the patient. The patient was evaluated thoroughly using clinical symptoms. The symptom of the patient was visible wart on the sole of foot and some pain on direct pressure on the wart.

The patient initially noticed a black dot on the sole of lateral aspect of mid foot which was painful on weight bearing and walking. She consulted a dermatologist regarding the same and was clinically diagnosed with a plantar wart. Dermatologist had done pairing for the wart approximately 5-7 times in an interval of 1-2 weeks. She was prescribed a mixture of salicylic acid and lactic acid ointment to be applied once daily. After that her symptoms worsened and she developed pain in weight bearing on the affected leg. On further follow-up the dermatologist had done Punch Excision and antibiotics were prescribed. The patient was then referred to physiotherapy OPD. Physiotherapy assessment of the patient was done. The patient had a wart on lateral plantar aspect of right foot with a diameter of approximately $1.3 \mathrm{~cm}$. The pain on NPRS (Numeric Pain rating scale) was 5 on weight bearing. Wart diameter was measured by vernier callipers with the patient in a sitting position with the affected foot exposed. The edge of the wart was marked using a fine tipped marker. The measuring caliper measured the diameter of the wart in centimeters. The measurements were done by the same physical therapist 3 times to ensure interrater reliability, before the first session, after the 7 th session and after the 15 th session. The patient also was diagnosed as having overpronated foot on weight bearing and walking. The physiotherapist advised ultrasonic therapy for plantar wart and exercises for correcting over pronation of the foot.

\section{THERAPEUTIC INTERVENTION}

The patient was given physiotherapy treatment including ultrasound therapy and exercises to correct over pronation of foot. Photographic evidence was taken at two-time intervals, one at the commencement of treatment (pre) and second after 15 weeks of treatment (post).

Protocol: Technique of Ultrasonic therapy: The ultrasonic equipment used in this case was Ultrasonic 1300 by EME, SRL Italy. The couplant used was ultrasonic gel. The gel ensures contact of the ultrasound head with the skin as the head is rotated on the skin with firm pressure. This technique is more effective due to higher energy transfer. If patient sensation is normal, a warmth will be noticed in the area. A dull aching indicates an intensity of too large a magnitude.

The dosage used was 0.6-1 watt/ $\mathrm{cm}^{2}$ with duration of treatment 15 minutes for each treatment session. The frequency of treatment used was one time per week for 15 weeks.

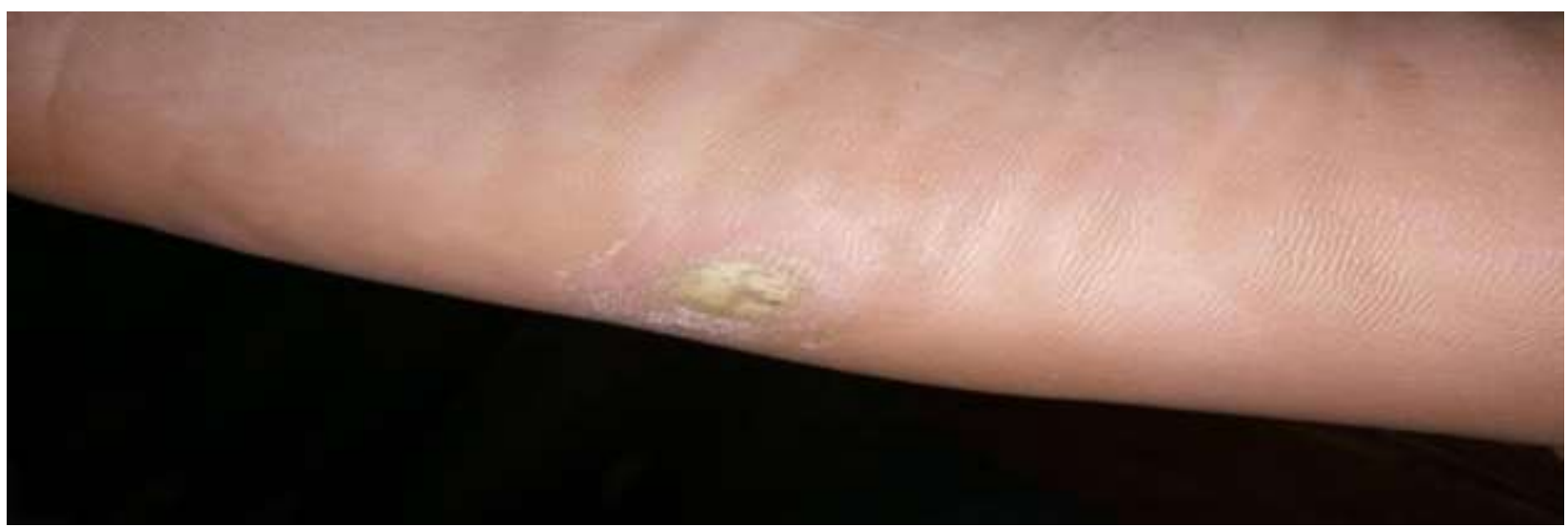

FIGURE 1: Plantar wart at the commencement of ultrasonic therapy

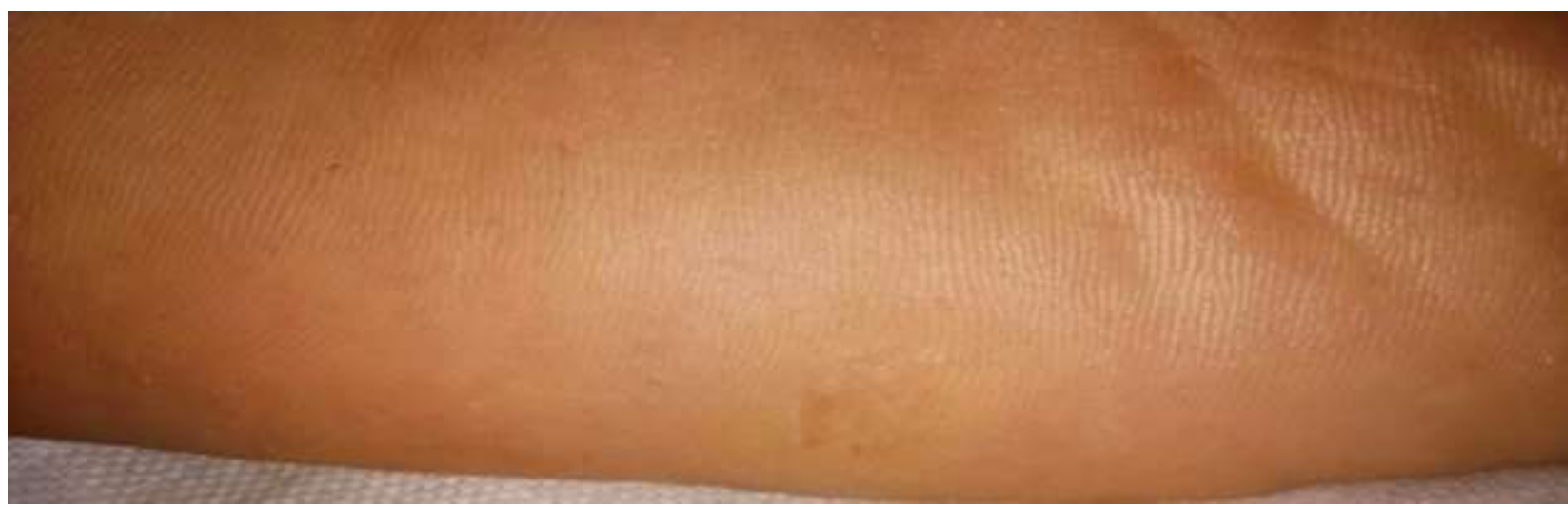

FIGURE 2: Plantar wart at the end of $15^{\text {th }}$ week of ultrasonic therap 
Protocol for pronated foot:

- Intrinsic foot muscle strengthening - towel curl, foam ball, heel to toe standing

- Invertors strengthening

- $\quad$ Evertor stretching

- Short foot exercise - pull first metatarsal toward heel without toe flexion maintain for 5 secs

- Hip and knee strengthening

- Balance training

Frequency and repetitions:

- Ultrasonic therapy was given once in a week for 15 weeks

- Exercise for pronated foot was done twice a day with 5 repetitions of each exercise started at the initial stage with progressive increments in the number of repetitions according to achievement of strength.

\section{RESULTS}

Improvement in pain was noted initially. After 6-7 treatment sessions slight improvement was noticed and completely disappearance of pain occurred after 10 treatment sessions. The scar remained, so treatment sessions continued and the scar improved. The pain on NPRS was 5 on weight bearing at 0 weeks, 3 at $7^{\text {th }}$ week and 0 at $15^{\text {th }}$ week. The wart diameter was $1.3 \mathrm{~cm}$ at o weeks, $0.8 \mathrm{~cm}$ at 7 weeks and $0 \mathrm{~cm}$ at 15 weeks.

\section{DISCUSSION}

Plantar warts cause pain while weight bearing and walking. Physiotherapy treatment included Ultrasound therapy for treating plantar wart and exercise for pronated foot. There was improvement in pain and skin became normal after Ultrasonic intervention. Whether the therapeutic effect is due to heat, psychotherapy or some other mechanism is not clear. The effective treatment technique seems to be an intensity of 0.6-1.0 watt $/ \mathrm{cm}^{2}$ for 15 -minute duration with one treatment session per week for 15 weeks. When the aqua sonic gel is directly applied to the skin it seems more effective. The number of treatment session required depends upon the age of plantar wart and method of previous treatment. With ultrasound treatment there is no scar tissue formation which is always present with surgery. Thus ultrasonic therapy seems to be effective treatment for plantar warts.

\section{CONCLUSION}

The present study concludes that ultrasound therapy is effective in treating patients suffering from plantar warts. Ultrasound therapy intervention improves pain and improves healing. Ultrasound seems to have value as an effective initial treatment program because of being painless, there is no scar formation and a comparatively inexpensive treatment. Ultrasound treatment allows the patient to continue with routine day to day activities and normal lifestyle while receiving treatment, something that may not be done with other methods of treatment. Another important aspect is there is no scar formation which is a risk with other established treatment methods.

\section{REFERENCES}

[1] Krishna SK, Jethwa AS. Human papillomavirus infections in adults and children. Am J Epidemiol Infect Dis. 2013;1(2):11-19. doi: 10.12691/ajeid-1-2-2

[2] Bruggink SC, Eekhof JA, Egberts PF, van Blijswijk SC, Assendelft WJ, Gussekloo J. Warts transmitted in families and schools: a prospective cohort. Pediatrics. .2013;131(5):928-934. doi: 10.1542/peds.2012-2946 [CrossRef]

[3] Clifton, M. M., S. M. Johnson, P. K. Roberson, J. Kincannon, and T. D. Horn, 2003. Immunotherapy for recalcitrant warts in children using intralesional mumps or Candida antigens. Pediatric dermatology, 20(3), 268-271.

[4] Sanclemente G, Gill DK. Human papillomavirus molecular biology and pathogenesis. J Eur Acad Dermatol Venereol. 2002;16(3):231-240. doi: 10.1046/j.1473-2165.2002.00419.x [CrossRef] [PubMed]

[5] Bruggink SC, Eekhof JA, Egberts PF, van Blijswijk SC, Assendelft WJ, Gussekloo J. Warts transmitted in families and schools: a prospective cohort. Pediatrics. .2013;131(5):928-934. doi: 10.1542/peds.2012-2946 [CrossRef]

[6] Khondker L, Shah MOR, Khan MSI. Verruca: need to know about human papilloma virus (HPV) infection.J Bangladesh Coll Phys Surg. 2012;30(3):151-158.

[7] Johnson LW. Communal showers and the risk of plantar warts. J Fam Pract.1995;40(2):136-138. [PubMed] Lipke MM. An armamentarium of wart treatments. Clin Med Res. 2006;4(4);273-293.[CrossRef] [PubMed]

[8] Cubie HA. Disease associated with human papillomavirus infection. Virol J. 2013; 445:21-34. [CrossRef]

[9] Silverberg JI, Silverberg NB. Childhood atopic dermatitis and warts are associated with increased risk of infection: a US population-based study. J Allergy Clin Immunol. 2014;133(4):1041-1047. [CrossRef] [PubMed]

[10] Cardoso JC, Calonje E. Cutaneous manifestations of human papillomaviruses: a review. Acta Dermatovenerol Alp Pannonica Adriat. 2011;20(3):145-154. [PubMed]

[11] Farhadian JA, Tlougan BE, Adams BB, Leventhal JS, Sanchez MR. Skin conditions of baseball, cricket, and softball players. Sports Med. 2013;43(7):575-589. doi: 10.1007/s40279-013-0022-4 [CrossRef] [PubMed]

[12] Silverberg JI, Silverberg NB. The US prevalence of common warts in childhood: a population-based study. J Invest Dermatol. 2013; 133:2788-2790. [CrossRef][PubMed] 
[13] Bradley A, Boyle D, Rossidis M. Efficacy of topical agents (SE, 5-FU, and IMQ) for treatment of verruca plantaris: a systematic review. Podiatr Med Rev. 2013-2014; 23:57-67.

[14] Akram S, Zaman H. Warts and verrucas: assessment and treatment. Pharm J.2015;294(7867). doi: 10.1211/PJ.2015.20068680

[15] Novasic T: Treatment of plantar warts with ultrasound. Phys Ther Rev 40383-884. 1960

[16] Rowe PJ, Gray JM: Ultrasound therapy of plantar warts. Arch Derm 82:1008-1009. 1960

[17] Cherup N, Urben J, Bender LF: The treatment of plantar warts with ultrasound. Arch Phys Med 44:602-604, 1963

[18] QuadeAG, RadzyminskiSF:Ultrasoundtherapyinverrucaplan- taris. J Am Pod 562503404, 1966

[19] Kent H: Plantar wart treatment with ultrasound. Arch Phys Med 40:15-18, 1959

[20] Griffin JE: What is the best method in the use of ultrasound for treatment of plantar warts? Phys Ther 5122. 1971

[21] Vaughn DT: Direct method versus underwater method in the treatment of plantar warts with ultrasound. Phys Ther 53:396- 397, 1973

[22] Braatz JH. McAlistar BR, Broaddus MD: Ultrasound and plantar warts; a double-blind study. Mili Med 139:199-201. 1974

[23] Casarotto RA, Adamowski JC, Fallopa F, Bacanelli F. Coupling agents in therapeutic ultrasound: acoustic and thermal behavior Arch Phys Med Rehabil. 2004 Jan;85(1):162-5. doi: 10.1016/s0003-9993(03)00293-4. PMID: 1497098

[24] Fred G Delacerda. Ultrasonic techniques for treatment of plantar warts in athletes. The Journal of Orthopedics and Sports Physical Therapy 1979.

[25] Claytons electrotherapy Forster and Palastanga 8th edition Electrotherapy explained: - Principles and Practice by John Low, Ann Reed $4^{\text {th }}$ edition 